\title{
Comparison of Lipid Profile in Type-2 Obese Diabetics and Obese Non-diabetic Individuals. A hospital Based Study from Western Nepal
}

\author{
Yadav NK, ${ }^{1}$ Thanpari $C,{ }^{2}$ Shrewastwa MK, ${ }^{2}$ Mittal RK ${ }^{3}$
}

${ }^{1}$ Department of Biochemistry, Manipal College of Medical Sciences, Pokhara, Nepal

${ }^{2}$ Department of Biochemistry, Nepalgunj Medical College, Chisapani, Banke, Nepal

${ }^{3}$ Department of Biochemistry, Nepalgunj Medical College, Chisapani, Banke, Nepal

\section{Corresponding Author}

Naval Kishor Yadav

Department of Biochemistry

Manipal College of Medical Sciences

Pokhara, Nepal

E-mail: naval.rhythm@gmail.com

\section{Citation}

Yadav NK, Thanpari C, Shrewastwa MK, Mittal RK. Comparison of Lipid Profile in Type-2 Obese Diabetics and Obese Non-diabetic Individuals. A hospital Based Study from Western Nepal. Kathmandu Univ Med J 2012;39(3):44-47.

\section{ABSTRACT \\ Background}

Type- 2 diabetes mellitus is an independent risk factor for coronary artery disease and risk of coronary disease is three to four fold increased in patients with diabetes compared with non-diabetic population and $60-80 \%$ of type-2 diabetics are obese.

\section{Methods}

This study was conducted in Nepalgunj Teaching Hospital, Kohalpur, Banke, Nepal, between 1st March, 2011 and 28th February, 2012. A total of 150 samples were taken to assess the lipid profile in type-2 diabetic patients associated with obesity and 25 obese controls for their lipid profile. Venous blood samples were taken from all the subjects in the morning after fasting overnight. Exclusion criteria included pregnancy, chronic infectious disease, heart failure; renal failure and drug allergy were confirmed from the subject's personal physician report and a detailed history. The data was analyzed using Excel 2003, R 2.8.0 Statistical Package for the Social Sciences (SPSS) for Windows Version 16.0 (SPSS Inc; Chicago, IL, USA) and the EPI Info 3.5.1 Windows Version.

\section{Results}

The mean \pm SD age of diabetic patients with obesity was $53.76 \pm 6.23$ while the mean \pm SD age of control was $49.61 \pm 4.8$. Out of 150 patients $105(70 \%)$ were males and $45(30 \%)$ were females. Among control subjects $16(64 \%)$ were males and $9(36 \%)$ were females. Obese type- 2 diabetic patients when compared to obese control subjects showed statistically significant increase in the levels of serum total cholesterol $(p<0.001)$, serum triglycerides $(p<0.001)$, serum LDL-cholesterol ( $p$ $<0.001$ ) while serum HDL-cholesterol levels did not show statistically significant difference in the two group $(p>0.05)$.

\section{Conclusion}

This study showed obese diabetic individuals have dyslipidemia and more prone to develop cardiovascular diseases.

\section{KEY WORDS}

Lipid profile, Type-2 diabetes mellitus, Obesity

\section{INTRODUCTION}

Diabetes mellitus (DM) is a serious health problem being the third greatest cause of death all over the world, and if not treated, it is responsible for many complications affecting various organs in the body. The prevalence of diabetes for all age-groups worldwide was estimated to be $2.8 \%$ in 2000 and $4.4 \%$ in 2030 . The total number of people with diabetes is projected to rise from 171 million in 2000 to 366 million in 2030. ${ }^{1}$ Type-2 diabetes mellitus is an independent risk factor for coronary artery disease and risk of coronary disease is three to four fold increased in patients with diabetes compared with non-diabetic population. ${ }^{2-4}$ Interestingly, in developed countries lower socioeconomic groups are most affected while in developing countries reverse applies. ${ }^{5}$ Diabetes is significant and related public health problem in those aged 40 or more in urban Nepal. ${ }^{6}$ It is calculated $60-80 \%$ of type-2 diabetics are obese. ${ }^{7}$ 
This study was conducted to examine the lipid profile in obese type- 2 diabetic patients and obese control group to correlate coronary heart disease with dyslipidemia.

\section{METHODS}

This study was conducted in Nepalgunj Teaching Hospital, Kohalpur, Banke, Nepal, between $1^{\text {st }}$ March, 2011 and $28^{\text {th }}$ February, 2012. A total of 150 samples were taken to assess the lipid profile in type- 2 diabetic patients associated with obesity and 25 obese controls for their lipid profile. Venous blood samples were taken from all the subjects in the morning after fasting overnight. Plasma levels of total cholesterol, triglycerides, High Density LipoproteinCholesterol (HDL-C), Low Density Lipoprotein-Cholesterol (LDL-C) were analyzed. Total cholesterol and triglycerides concentration were determined with semi-automated enzymatic analyzer. Serum HDL-Cholesterol level was measured by using phospho-tungstate precipitation method. Serum LDL-C was calculated according to computational procedures of Friedewald et al. ${ }^{8}$ The internal quality control was included in each batch of tests performed. Inclusion criteria: The patients having confirmed diabetes mellitus with BMI more than $30 \mathrm{~kg} /$ $\mathrm{m}^{2}$ were included in this study. Exclusion criteria included pregnancy, chronic infectious disease, heart failure; renal failure and drug allergy were confirmed from the subject's personal physician report and a detailed. Ethical approval for the study was taken from the institutional research ethical committee. The data was analyzed using Excel 2003, R 2.8.0 Statistical Package for the Social Sciences (SPSS) for Windows Version 16.0 (SPSS Inc; Chicago, IL, USA) and the EPI Info 3.5.1 Windows Version. The t-test was used to observe the relationship between different variables. $p<$ 0.05 is considered as statistically significant.

\section{RESULTS}

The study was conducted on 150 type- 2 diabetic patients associated with obesity and 25 obese age and sex matched controls. The mean \pm SD age of diabetic patients with obesity was $53.76 \pm 6.23$ while the mean \pm SD age of control was $49.61 \pm 4.8$. Out of 150 patients 105 (70\%) were males and 45 (30\%) were females. Among control subjects 16 (64\%) were males and 9 (36\%) were females (table 1).

Table 1. Age and sex distribution of study subjects.

\begin{tabular}{|lll|}
\hline & $\begin{array}{l}\text { Obese type-2 diabetic } \\
\text { patients }\end{array}$ & Obese control \\
\hline Age in years (range) & $30-65$ & $30-62$ \\
\hline Mean \pm SD & $53.76 \pm 6.23$ & $49.61 \pm 4.8$ \\
\hline Sex distribution & & \\
\hline Males & $105(70 \%)$ & $16(64 \%)$ \\
\hline Females & $45(30 \%)$ & $9(36 \%)$ \\
\hline
\end{tabular}

Obese type-2 diabetic patients when compared to obese control subjects showed statistically significant increase in the levels of serum total cholesterol $(p<0.001)$, serum triglycerides $(p<0.001)$, serum LDL-cholesterol $(p<0.001)$ while serum HDL-cholesterol levels did not show statistically significant difference in the two group $(p>0.05)$ (table 2 ). A comparison of lipid profile of obese type-2 diabetic patients and obese control group were represented in fig 1 .

\section{Table 2. Lipid profile of patient and control subjects.}

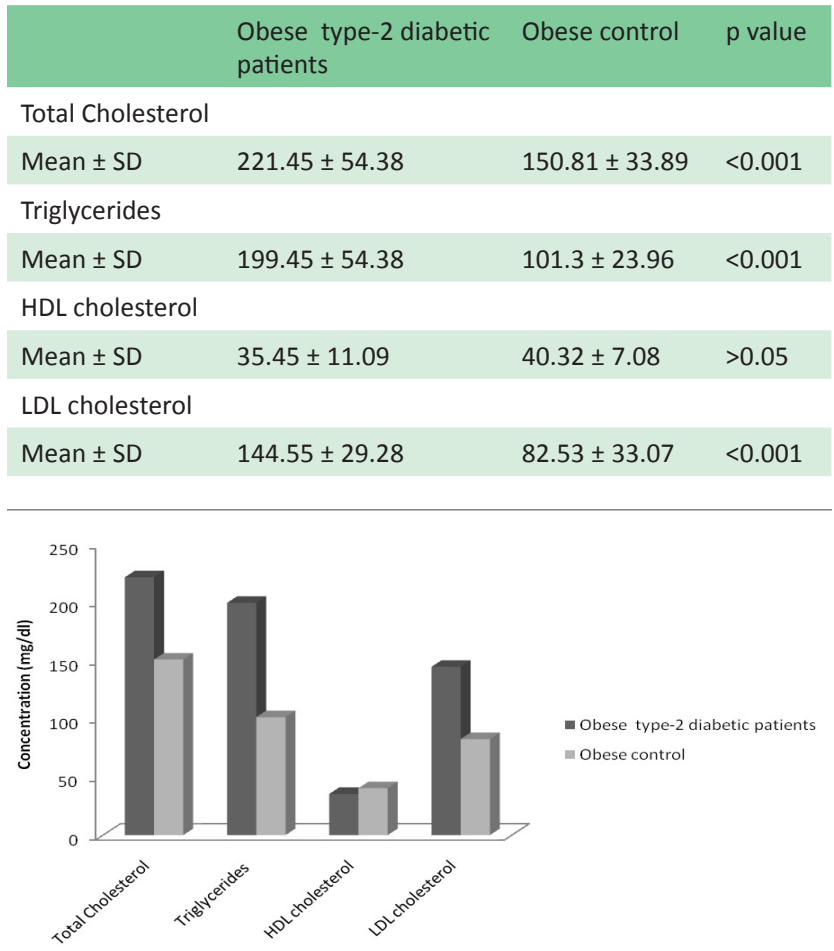

Figure 1. A comparison of lipid profile of obese type-2 diabetic patients and obese control group.

\section{DISCUSSION}

Dyslipidemia is very common in type 2 diabetes and it is characterized by hypertriglyceridemia and low levels of HDL-C. ${ }^{9}$ Hypertriglyceridemia predisposes the patients to life threatening complications like diabetic ketoacidosis, coronary artery disease and lipaemia retanalis. ${ }^{10}$ It is more common in diabetics as compared to nondiabetics due to four fold increase in VLDL triglyceride. ${ }^{11}$ Hypercholesterolemia and high level of LDL-C mainly oxidized LDL-C in blood causes development of plague formation and finally atherosclerosis as well as other cardiac diseases.

In our study, obese diabetics when compared to obese control subjects showed statistically significant increase in the levels of serum total cholesterol $(P<0.001)$, serum triglycerides $(P<0.001)$ and serum $L D L$-cholesterol $(P$ $<0.001)$. Serum HDL - cholesterol levels did not differ significantly $(P>0.05)$ in the two groups but level were low in obese diabetic compare to obese controls. The studies of Santen et al (1972) and Peret et al (1974) observed 
mean serum triglyceride levels higher in obese diabetics in comparison to obese control subject. ${ }^{12,13}$ Sharma (1970) and Jain (1980) observed increase in the levels of serum total lipids, total cholesterol, serum triglycerides and serum phospholipids in diabetic subjects as compared to normal controls. ${ }^{14,15}$ Several other studies have shown similar results as were obtained in our study $(16,17,18)$.

Obesity and type 2 diabetes mellitus are associated with increased deposition of triglycerides in nonadipose tissue, such as the heart, liver, pancreas, and skeletal muscle. ${ }^{19}$ Obesity, i.e. fat accumulation in the subcutaneous abdominal and visceral depots, is most strongly associated with the risk of metabolic and cardiovascular complications. ${ }^{20-22}$ Visceral obesity plays an important role in the development of diabetes by mobilizing free fatty acids and certain inflammatory cytokines promoting insulin resistance. ${ }^{23}$ In obesity, the low plasma HDL-C levels have been attributed to increased fractional clearance of HDL secondary to depletion of its cholesterol. ${ }^{24,25}$ Many key enzymes involved in HDL metabolism are altered in obese people with insulin resistance. Some of these changes are further developed in type 2 diabetes where in addition to insulin resistance, relative or absolute insulin deficiency. An important metabolic trigger for reduced HDL-C levels in obesity and insulin resistance is the increased VLDL production, at least partly because of increased fatty acid flux to the liver. ${ }^{26}$ Gambhir et al found that low HDL were independent risk factor for premature coronary artery disease. ${ }^{27} \mathrm{HDL}$ facilitates reverse cholesterol transport to the liver from peripheral tissues, and thus probably prevents vascular atherosclerotic lesions from developing. ${ }^{28}$ The cardioprotective properties of HDL include antioxidant activity, anti-inflammatory activity and scavenging toxic byproducts of LDL oxidation such as lysophosphatidylcholine, antithrombotic and fibrinolytic activity through promotion of protein $\mathrm{C}$, and inhibition of LDL retention through apo E-related effects. ${ }^{29-31}$ Schmitt et al reported LDL uptake by fibroblasts may be impaired in type 2 diabetes and this leads to increase in LDL: HDL ratio in type 2 diabetics. ${ }^{32}$ Patients with type-2 diabetes have increased risk of cardiovascular disease associated with atherogenic dyslipidemia and coronary artery disease, especially myocardial infarction is the leading cause of morbidity and mortality worldwide. ${ }^{33}$ This signifies individuals having diabetes associated obesity are more prone to develop cardiovascular disease then obese non- diabetic individuals.

\section{CONCLUSION}

This study showed obese diabetic individuals have dyslipidemia and more prone to develop cardiovascular diseases. The most probable reason, people are more aware of their physical well-being, changing their dietary habits and life style modification.

\section{REFERENCES}

1. Wild S, Roglic G, Green A, Sicree R, King H. Global prevalence of diabetes: estimates for the year 2000 and projections for 2030. Diabetes Care 2004; 27(5):1047-53.

2. Garcia MJ, McNamara PM, Gordon T, Kannel WB. Morbidity and mortality in diabetics in the Framingham popultion, sixteen year follow-up study. Diabetes 1974; 23(2):105-11.

3. Kannel WB, McGee DL. Diabetes and cardiovascular risk factors: the Framingham study. Circulation 1979; 59(1):8-13.

4. Ruiz J, Thillet J, Huby T, James RW, Erlich D, Flandre P, et al. Association of elevated lipoprotein(a) levels and coronary heart disease in NIDDM patients. Relationship with apolipoprotein(a) phenotypes. Diabetologia 1994; 37(6):585-91.

5. Mohan V, Shanthirani S, Deepa R, Premalatha G, Sastry NG, Saroja R. Intra urban differences in the prevalence of the metabolic syndrome in southern India, the Chennai urban population study. Diabet Med 2001; 18(4):280-7.

6. Khattri JB, Nepal MK. Study of depression among geriatric population in Nepal. Nepal Med Coll J 2006; 8(4):220-3.

7. Sheth JJ. Diabetes, microalbuminuria and hypertension. Clin Exp Hypertens 1999; 21(1-2):61-8.

8. Friedewald WT, Levy RI, Fredrickson DS. Estimation of the concentration of low-density lipoprotein cholesterol in plasma, without use of the preparative ultracentrifuge. Clin Chem 1972; 18(6): 499-502.

9. Betterridge DJ. Diabetic dyslipidemia. Diabetes Care 2000; 2(Suppl 1): 31-6.

10. Oh RC, Lanier JB. Management of Hypertriglyceridemia. Am Fam Physician 2007; 75(9): 1365-71.
11. Arbeeny CM, Nordin C, Edelstein D, Stran N, Gibbons N, Eder HA. Hyperlipoproteinimia in spontaneously diabetic guinea pigs. Metabolism 1989; 38: 895-900.

12. Santen RJ, Willis PW, Fajans SS. Atherosclerosis in diabetes mellitus. Correlations with serum lipid levels, adiposity, and serum insulin level. Arch Intern Med 1972; 130(6): 833-43.

13. Perrett AD, Rowe AS, Shahmanesh M, Allison SP, Hartog M. Blood lipids in treated diabetics. Diabetologia 1974; 10(2): 115-8.

14. Sharma D, Bansal BC, Prakash C. Serum lipid studies in thin insulin dependent diabetics below the age of 30 years. J Indian Med Assoc 1970; 54(9):416-20.

15. Jain AP and Gupta DP. Study of blood lipid in Diabetics without any manifest vascular complications. J.Dia. Asso. Ind 1980; 199:29-34.

16. Cohen AM, Fidel J, Cohen B, Furst A, Eisenberg S. Diabetes, blood lipids, lipoproteins, and change of environment: restudy of the "new immigrant Yemenites" in Israel. Metabolism 1979; 28(7):716-28.

17. Bijlani PK, Shah K, Raheja BS, Krishnaswamy PR. High density lipoprotein cholesterol in diabetes. J Assoc Physicians India 1984; 32(4):309-11.

18. Zargar AH, Wandroo FA, Wadhwa MB, Laway BA, Masoodi SR, Shah NA. Serum lipid profile in non-insulin-dependent diabetes mellitus associated with obesity. Int. j. diab. Dev. Countries 1995; 15:9-13.

19. Tushuizen ME, Bunck MC, Pouwels PJ, Bontemps S, van Waesberghe $\mathrm{JH}$, Schindhelm RK, et al. Pancreatic fat content and beta-cell function in men with and without type 2 diabetes. Diabetes Care 2007; 30: 2916-21.

20. Kissebah AH \& Krakower GR. Regional adiposity and morbidity. Physiol Rev 1994; 74: 761-811. 
21. Abate N \& Garg A. Heterogeneity in adipose tissue metabolism: causes, implications and management of regional adiposity. Prog Lipid Res 1995; 34: 53-70.

22. Arner P. Not all fat is alike. Lancet 1998; 351: 1301-1302.

23. Kadowaki T \& Yamauchi T. Adiponectin and adiponectin receptors. Endocrine Rev 2005; 26:439-451.

24. Borggreve SE, De Vries R, Dullaart RP. Alterations in high-density lipoprotein metabolism and reverse cholesterol transport in insulin resistance and type 2 diabetes mellitus: role of lipolytic enzymes, lecithin: cholesterol acyltransferase and lipid transfer proteins. Eur J Clin Invest 2003; 33: 1051-1069.

25. Vajo Z, Terry JG, Brinton EA. Increased intra-abdominal fat may lower HDL levels by increasing the fractional catabolic rate of Lp A-I in postmenopausal women. Atherosclerosis 2002; 160: 495-501.

26. Semenkovich CF. Insulin resistance and atherosclerosis. J Clin Invest 2006; 116: 1813-1822.

27. Gambhir JK, Kaur H, Gambhir DS, Prabhu KM. Lipoprotein (a) as an independent risk factor for coronary artery disease in patients below 40 years of age. Indian Heart J 2002; 52: 411-5.
28. Gordon T, Castelli WP, Hjortland MC, Kannel WB, Dawber TR. High density lipoprotein as a protective factor against coronary heart disease. The Framingham Study. Am J Med 1977; 62: 707-714.

29. Mooradian AD, Haas MJ, Wong NCW. The effect of select nutrients on serum high density lipoprotein cholesterol and apolipoprotein A-I levels. Endocr Rev 2006; 27: 2-16.

30. Mooradian AD, Haas MJ, Wong NCW. Transcriptional control of apolipoprotein A-I gene expression in diabetes mellitus. Diabetes 2004; 53: 513-520.

31. Hachem S, Mooradian AD. Familial dyslipidemias: an overview of pathophysiology and management. Drugs 2006; 66: 1949-1969.

32. Schmitt JK, Poole JR, Lewis SB. Hemoglobin A1 correlates with the ratio of low to high density lipoprotein in normal weight type 2 diabetics. Metabolism 1982; 31: 1084-9.

33. Toth PP. Effective management of the type 2 diabetes patient with cardiovascular and renal disease: secondary prevention strategies after a myocardial infarction. Curr Diabetes Rev 2012; 8(3): 219-28. 